\title{
Palliative Endoscopic Treatment Options in Malignancies of the Biliopancreatic System
}

\author{
Jürgen Feisthammel Joachim Mössner Albrecht Hoffmeister \\ Division of Gastroenterology and Rheumatology, Department of Internal Medicine, Neurology and Dermatology, \\ University Hospital of Leipzig, Leipzig, Germany
}

\section{Keywords}

Pancreatic cancer - Biliary tract cancer - Klatskin tumor . Endoscopy · Stent · Photodynamic therapy · PDT · Radiofrequency ablation · RFA

\section{Summary}

In most of the cases, pancreatic cancer and malignancies of the bile tract can only be treated palliatively. Endoscopy offers several methods for effective control of the symptoms in those situations. In pancreatic cancer, stenting of bile ducts enables a control of jaundice most of the time. Stenting of an obstructed duodenum can relieve symptoms of gastric outlet obstruction without the need for major surgery. In biliary tract cancer, stenting of the bile ducts can provide effective drainage of the biliary system. Photodynamic therapy and radiofrequency ablation can sometimes be a valuable tool in symptom control. This review tries to provide an overview on endoscopic palliative treatment options in pancreatic cancer and biliary tract cancer.

\section{Introduction}

In 2010, according to data of the German 'Robert KochInstitut' (central federal institution responsible for disease control and prevention), there were about 16,000 patients with newly diagnosed pancreatic cancer and 5,300 patients with newly diagnosed cancer of the biliary tract (bile duct and gall bladder) in Germany. The majority of these tumors were adenocarcinomas [1].

In both types of cancer the only way of curing the disease is surgical resection. However, at the time of initial diagnosis the

\section{Schlüsselwörter}

Pankreaskarzinom · Gallengangskarzinom · KlatskinTumor - Endoskopie - Stent - Photodynamische Therapie . PDT · Radiofrequenzablation · RFA

\section{Zusammenfassung}

Das Behandlungsziel von Karzinomen an Pankreas und Gallenwegen muss in den meisten Fällen palliativ bleiben. In diesen Situationen kann die Endoskopie verschiedene Behandlungsoptionen zur effektiven Symptomkontrolle bieten. Bei Pankreaskarzinomen kann ein Stauungsikterus meist mittels Stentimplantation erfolgreich therapiert werden. Eine Magenausgangsstenose kann durch einen Duodenalstent effektiv beseitigt werden. Auch bei Malignomen der Gallenwege ist die Stentimplantation ein erfolgreiches Verfahren zur Sicherstellung der Gallendrainage. In manchen Fällen kann dies erfolgreich durch die photodynamische Therapie und die Radiofrequenzablation unterstützt werden. Die vorliegende Übersichtsarbeit versucht, die zur Verfügung stehenden Therapieoptionen einzuordnen und deren Indikationen und Limitationen zu beleuchten.

disease is resectable in only $15-20 \%$ of the cases. Most of the patients require palliative management. Usually the patients will receive cytostatic chemotherapy $[2,3]$.

Patients with biliopancreatic malignancies often have specific tumor-derived symptoms such as stenoses of the biliary tract or gastric outlet obstruction (GOO). In those cases, endoscopy can play an important role in the management of symptom control.

In the following, we will provide an overview of endoscopic treatment options in the management and palliative care of patients with biliopancreatic cancer.

\begin{tabular}{ll}
\hline KARGER & $\begin{array}{l}\text { (1) 2014 S. Karger GmbH, Freiburg } \\
1662-6664 / 14 / 0304-0238 \$ 39.50 / 0\end{array}$ \\
$\begin{array}{l}\text { Fax +49 7614520714 } \\
\text { Information@Karger.com } \\
\text { www.karger.com }\end{array}$ & $\begin{array}{l}\text { Accessible online at: } \\
\text { www.karger.com/vim }\end{array}$
\end{tabular}


Fig. 1. ERCP of a patient with carcinoma of the head of the pancreas with biliary obstruction. A Radiographic image of a high-grade stenosis of the bile duct (along the black asterisks). B Radiographic image after placement of a self-expanding metal stent (SEMS, along white asterisks) in the bile duct completely bridging the stenosis. C Endoscopic view of the SEMS as seen from the duodenum.

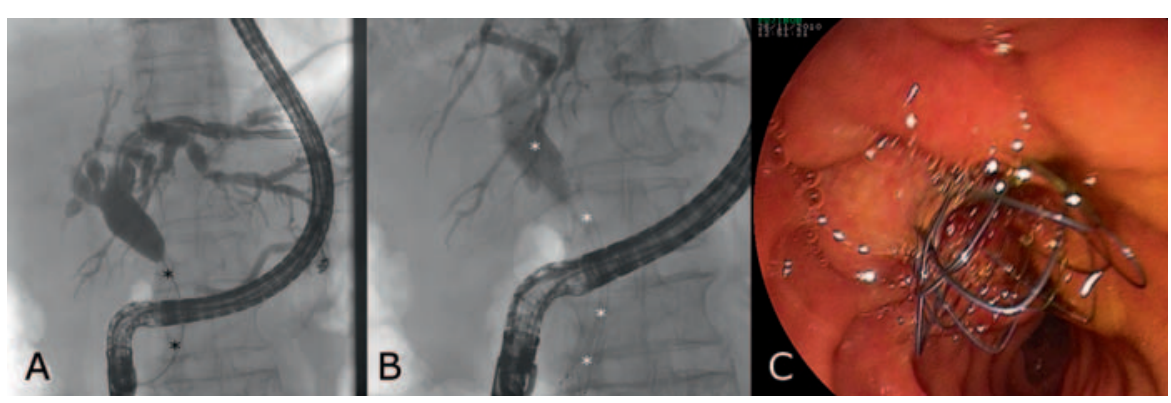

\section{Pancreatic Cancer}

Clinical presentation of patients with pancreatic cancer depends on the location of the tumor lesion. While tumors of the tail and the body of the pancreas are often causing non-specific complaints and therefore are frequently not diagnosed until advanced stage, tumors of the head of the pancreas may present earlier due to jaundice. The majority of pancreatic cancers are located in the head, and at this location bile duct and duodenum are often affected due to their anatomical proximity. Stenosis of the biliary tract may occur at an early stage of the disease, thus leading to jaundice as a symptom and, subsequently, the patient seeking medical help. However, GOO caused by duodenal infiltration of the tumor is typically a rather late symptom in an already advanced tumor stage [3].

\section{Obstructions of the Bile Duct}

Sooner or later up to $70 \%$ of the patients with pancreatic cancer suffer from obstructive jaundice [3]. Tumors of the pancreatic head often directly compress the common bile duct. Those patients typically suffer from obstructive jaundice in a still early stage of the cancer. Tumors of the pancreatic body or tail almost never affect the bile duct directly. However, in that case infiltrated and enlarged lymph nodes at the hilum of the liver can also be responsible for an obstruction of the biliary tract. Obstructive jaundice typically occurs at an advanced stage of cancer in those patients.

It is important to treat obstructive jaundice in patients with pancreatic cancer as this condition causes pruritus, increases the risk of cholangitis, and can impair the function of the liver. Surgery (e.g. choledochojejunostomy) has been the 'classic' approach in the treatment of patients with obstructive jaundice. However, as this procedure has a relevant mortality and morbidity (3 and $22 \%$, respectively) without improving survival compared to stenting ( 6.5 months), it has been replaced by endoscopic stenting [4]. Nowadays, choledochojejunostomy is sometimes performed during planned surgery of pancreatic cancer when the tumor proves to be unresectable. However, biliary stenting is reported to be as effective as surgery. Thus, surgery usually plays no longer a role in the man-
Fig. 2. Radiographic image after placement of a SEMS (along white asterisks) via percutaneous access (PTCD technique, along black asterisks).

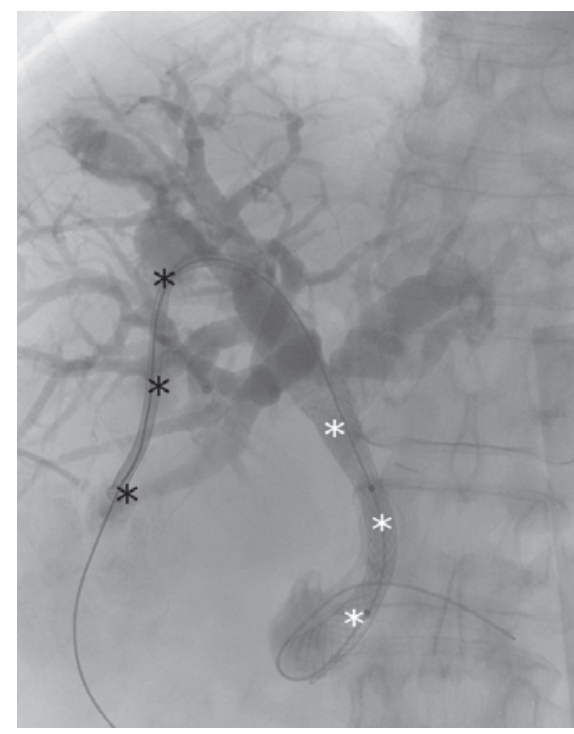

agement of obstructive jaundice in patients with pancreatic cancer $[5,6]$.

Stents are usually quite successful in the treatment of patients with obstructive jaundice. Stent placement has a lower mortality and morbidity compared to surgery but entails more risks for stent occlusion, dislocation, and cholangitis [7, 8]. It is important to identify patients with jaundice due to impaired liver function (e.g. multiple liver metastases) and without ultrasonographic signs of obstruction of the large bile ducts as those patients usually do not benefit from biliary stenting.

An important question which has to be answered before stenting patients with obstructive jaundice is whether to use plastic stents (PS) or self-expandable metal stents (SEMS). The most important differences between both groups of stents are as follows: SEMS are larger in diameter compared to PS. This is the reason why SEMS have a longer duration of stent patency [8]. PS may get obstructed by sludge. Thus, PS have to be exchanged every 3 months to diminish the risk of ascending cholangitis. In cases of cholangitis \pm cholestasis, stents have to be exchanged immediately in order to prevent biliary sepsis. SEMS do not require a scheduled exchange, albeit occlusion of uncovered SEMS due to tumor ingrowth occurs in patients with pancreatic cancer in up to $27 \%$ of the cases [9]. SEMS are more expensive than PS. The latter can be easily 


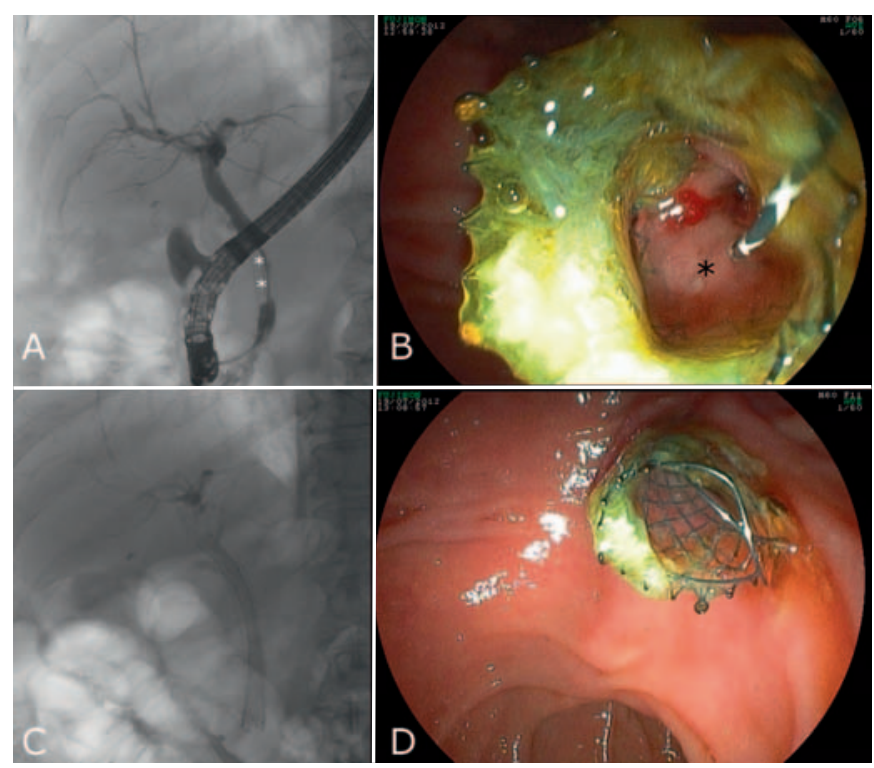

Fig. 3. Restenosis of the bile duct after previous placement of a SEMS due to tumor ingrowth. A Radiographic image of the in-stent stenosis (along white asterisks). B Endoscopic view of tumor masses (black asterisk) inside the uncovered SEMS along the bile duct. C Radiographic image after placement of a SEMS inside the obstructed SEMS (stent-instent technique). D Endoscopic view after placement of a SEMS inside the existing SEMS.

removed while SEMS without cover are difficult if not impossible to remove endoscopically. SEMS without cover usually do not migrate while PS sometimes dislocate or migrate causing jaundice and cholangitis with the need of replacing the stents [10].

PS are available from 7 to 11.5 French $(\mathrm{Fr})$ in diameter and in lengths ranging between 5 and $15 \mathrm{~cm}$. As early re-obstruction of the stents occasionally occurs when diameters of less than $10 \mathrm{Fr}$ are used, stents of 10 or $11.5 \mathrm{Fr}$ are mostly used in palliative care $[11,12]$. The length depends on the position of the stenosis. SEMS for use in the bile ducts are almost always $30 \mathrm{Fr}$ in diameter as smaller diameters tend to obstruct significantly faster [9]. SEMS are usually available from 4 to $10 \mathrm{~cm}$ in length.

The right choice of stent depends on the location of the obstruction, expected length of survival, and expertise of the physician [8]. As SEMS may not be removable it is necessary to have proven malignancy. If the diagnosis is unclear, PS should be used until staging is completed as these stents can be removed easily. In pancreatic cancer, the site of obstruction is often localized in the distal bile duct. In those cases placement of SEMS is often realizable. In palliative care, removability of stents is usually not necessary. Therefore, the stent of choice will be in most cases a SEMS without cover (fig. 1), as covered stents have the risk to migrate and dislocate [8]. In a study on 112 patients, covered and uncovered stents have been compared. This study showed a longer patency of covered stents due to less tumor ingrowth; however, this type of stent had a higher rate of complications compared to uncovered stents. Regarding overall survival there is no difference between covered or uncovered stents. Thus, uncovered stents are usually recommended [13].

Biliary stents are usually placed during endoscopic retrograde cholangiopancreaticography (ERCP). After major abdominal surgery or with duodenal obstruction, the ampulla of Vater sometimes cannot be reached by ERCP. In this case, percutaneous placement of SEMS by PTCD (percutaneous transhepatic cholangio drainage) technique may be helpful (fig. 2) [14].

In cases where a previously placed uncovered SEMS gets obstructed by debris or tumor ingrowth, a sweeping of the stent by means of an occlusion balloon can be helpful. If sweeping is not sufficient to relieve the obstruction, a placement of stents inside the obstructed SEMS is mandatory. In that case, PS or another SEMS can be applied (stent-in-stent technique) (fig. 3).

Sometimes it is a matter of discussion whether or not patients with resectable disease will benefit from biliary stenting prior to surgery. According to a recent study, patients with preoperative ERCP for biliary drainage had more complications as compared to patients treated by surgery alone [15]. Therefore, biliary drainage should only be performed in cases of cholangitis or in cases where surgery will be delayed. In those cases, the placement of a metal stent should be considered.

\section{Gastric Outlet Obstruction}

GOO is quite often caused by pancreatic cancer [16]. In most of the cases, GOO in patients with advanced pancreatic cancer is caused by direct compression or tumorous infiltration of the duodenum. GOO occurs in up to $25 \%$ of the patients, usually in a rather late tumor stage [17]. The patients suffer from nausea, vomiting, dehydration with impairment of electrolyte balance, and malnutrition, which are lifethreatening conditions for patients with pancreatic cancer. The most important goal for patients with GOO is to restore the ability to eat.

In cases where pancreatic carcinoma proves to be unresectable during surgery, some surgeons perform gastroenterostomy (GE) to prevent duodenal obstruction. In 2009, a metaanalysis showed this procedure to be beneficial for the patients [18]. Apart from those cases with prophylactic GE, endoscopic placement of a SEMS is the treatment of choice in cases of tumor-derived duodenal obstruction. Usually, this procedure is able to solve the problem with at least partial relief of the symptoms.

Sufficient stenting of duodenal obstruction can be performed with covered or uncovered SEMS. While uncovered stents are more prone to tumor ingrowth with obstruction of the stent, they are less prone to dislocate compared to cov- 


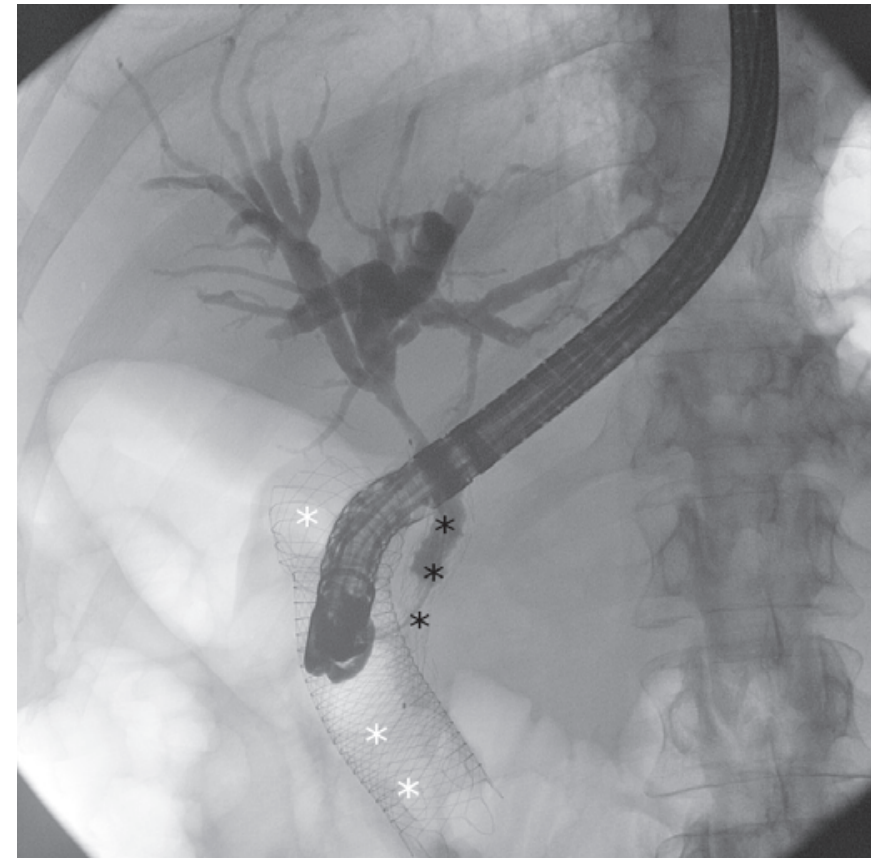

Fig. 4. Patient with stenosis of the bile duct and of the duodenum. The SEMS of the bile duct (along black asterisks) should be placed before placement of the SEMS of the duodenum (along white asterisks).

ered stents. In cases where the stent is placed across the ampulla, covered stents would cause biliary obstruction and increase the risk of both pancreatitis and cholangitis. Thus, uncovered stents are commonly used for the treatment of duodenal obstruction. The stents are typically $20-22 \mathrm{~mm}$ in diameter and 6-12 $\mathrm{cm}$ in length.

In a meta-analysis from $2007,89 \%$ of the patients had a clinical benefit with relief of symptoms after the placement of a duodenal stent [17]. The hospital stay was much shorter compared to surgical GE (7 vs. 13 days). Both groups had almost the same rate of major and minor complications. Especially for patients with an estimated life expectancy of less than 6 months, stenting is the treatment of choice and preferable over surgery. Surgery may be considered in patients with a higher life expectancy. In patients with peritoneal carcinomatosis, however, surgery should not be performed because of an expected impairment of wound healing.

Prior to duodenal stent placement it is important to ensure sufficient biliary drainage. Patients with duodenal obstruction caused by pancreatic cancer are usually at risk to develop biliary obstruction. Furthermore, most of the time patients with GOO already have stents in their biliary system. It is important to recognize that biliary stenting may not be realizable via ERCP after placing a duodenal stent across the ampulla of Vater. In those cases it is important to place a SEMS into the biliary tract before placing the duodenal stent (fig. 4) [19]. It is crucial to apply an uncovered duodenal SEMS to prevent obstruction of both the biliary and the pancreatic ducts.

\section{Bile Duct Cancer}

Bile duct cancer is a rather rare malignant tumor of the biliary tract. It can occur anywhere along the biliary system. Biliary tract cancers are divided into intrahepatic and extrahepatic cholangiocarcinomas, cancers of the gallbladder, and cancers of the ampulla of Vater. While intrahepatic cholangiocarcinomas are only rarely causing obstructive jaundice, which is treatable by endoscopic procedures, obstructions caused from cancers at the hilus (Klatskin tumor), the extrahepatic bile ducts, the gallbladder, and the ampulla are usually relievable by endoscopic stent placement. About twothirds of bile duct cancers are located at the hilum as so-called Klatskin tumors [20]. At the time of diagnosis about twothirds of the tumors are unresectable [2].

\section{Biliary Obstruction}

Biliary obstruction is the major clinical complaint of patients with cancer of the biliary system. While intrahepatic cholangiocarcinomas are typically not causing obstructive jaundice, most of the patients with extrahepactic cholangiocarcinoma (i.e. Klatskin tumors) and gallbladder cancer suffer from obstructive jaundice.

In general, the principles of stenting as stated above in the section about pancreatic carcinoma are also applicable in cases with bile duct cancer. However, there are also some differences to be found.

Biliary stents are used for bridging until surgery is performed; stents are also used in palliative care. In cases where staging is not yet completed and the need for surgery remains unclear, PS are typically used. In obstructions distal of the hilum, the treatment of choice is stenting with uncoated SEMS. Coated SEMS are increasing the risk of cholecystitis [8]. Stent placement in distal stenoses can usually be performed without major complications and rather rapidly provides sufficient drainage of the bile duct. In the case of hilar obstruction, endoscopic stenting often is technically more difficult. Standard-shaped SEMS cannot be placed at the hilum because the stent would only drain one half of the liver while the other half would not be drained sufficiently. PS are the treatment of choice in those cases. Up to 3 PS are commonly inserted to bridge the stenosis. In order to minimise the risk of early stent obstruction, stents of at least $10 \mathrm{Fr}$ in diameter should be used. With 10 Fr stents, an exchange is needed every 3 months to prevent cholangitis. PS should also be used when the expected lifespan is shorter than 3-6 months. In these cases an exchange of the PS is not needed anymore. Furthermore, PS are more cost-effective than SEMS, with less risk for the patient.

Another well-known option for palliative treatment of biliary tract cancer is photodynamic therapy (PDT). To perform this procedure the patients need to receive photosensitizers 
like intravenous porphyrins about $48 \mathrm{~h}$ prior to a planned PDT procedure. PDT is done during ERCP by application of light (usually red laser light, wavelength depends on the type of photosensitizer) over an optical fiber placed inside the bile ducts next to the tumor stenosis. The applied light energy interacts with the photosensitizer causing cell death via generation of oxygen free radicals. Due to limited depth of penetration of light energy, this procedure is usually not feasible for curative intent [21]. PDT can only be performed in patients with bile duct stenoses which can be reached by fibers placed by either ERC or PTC. Gallbladder cancer cannot be treated by this technique. The typical patient who will benefit from this option has a Klatskin tumor. Stenting of the branches of the biliary tree which were treated by PDT is mandatory due to the risk of biliary obstruction caused by inflammatory edema after PDT. PDT is usually performed every 6 months. As special equipment is needed, PDT is not widely available.

Two randomized trials have been performed with PDT. Both studies showed significantly longer survival rates accompanied by an improved biliary drainage and improved quality of life. It is still not known whether the prolonged survival is due to improved biliary drainage when PDT is combined with stenting versus stenting alone or whether the additional inhibition of tumor growth by PDT plays any role. Reported complications of PDT are cholangitis and liver abscess [22, 23].

Another endoscopic option in the treatment of bile duct cancer is intraductal radiofrequency ablation (RFA). This procedure seems to be more easily available than PDT as less specific equipment is needed. An RFA catheter is inserted into the bile ducts via the working channel of the ERCP endoscope. To date, no prospective data are available. Recently published retrospective data suggest RFA to be successful and reliable. Important complications in two retrospective studies were liver infarction and hemobilia [24, 25]. 2 of 12 patients treated in one of the series died due to hemorrhagic shock. Hence, safety issues are linked to this treatment, and larger studies are especially needed to address the safety of RFA. An arguable advantage of this treatment is that the procedure does not require any planning days in advance as is the case with PDT (which needs intravenous administration of photosensitizer 1-4 days prior to the procedure). RFA is readily available and can be performed during the same ERCP session.
A possible new option in the palliative treatment of biliary tract cancer could be the photochemical internalisation of drugs for cytostatic chemotherapy. This technique is using photosensitizing agents such as disulfonated tetraphenyl chlorin (TPCS2a) intravenously [26, 27]. In a second step, light is applied to the bile duct (analog PDT technique as described above). The third step would be the application of cytostatic chemotherapy. Recently, a multicentric phase I/II trial was started for the further study of this new treatment option (PCI A202/12; ClinicalTrials.gov identifier: NCT01900158).

\section{Conclusion}

In patients with pancreatic cancer and bile duct cancer there are several disease-specific complications (as described above). In general, most often tumor-derived obstructions of the biliary tract or duodenum are causing complaints. Usually, endoscopic treatment is feasible to at least partially relieve the patients' complaints. In early stages of obstructive jaundice, biliary stenting is easier and safer than in the advanced stage. Endoscopic stenting may be technically impossible in advanced stage obstructive jaundice, thus being replaced by a percutaneous drainage (PTCD). This kind of drainage usually impairs quality of life more than endoscopic stenting. Most of the procedures and techniques discussed here are well studied and readily available. However, PDT usually is only available in hospitals of maximal care. Due to the reported cases of lethal hemobilia, the role of RFA still remains unclear. Further studies have to address these safety issues. All the methods described here are palliative means, and none of them allows curing the patient. Despite recent studies showing promising effects of chemotherapy on the survival of patients with pancreatic cancer, treatment remains palliative in the majority of cases [28, 29].

\section{Disclosure Statement}

The authors disclose any sponsorship or funding arrangements relating to their research. All authors disclose any possible conflicts of interest.

\section{References}

1 Robert Koch-Institut: Krebs in Deutschland. $w w w$. rki.de/Krebs/DE/Content/Publikationen/Krebs_in Deutschland/krebs_in_deutschland_inhalt.html? $n n=2378942$.

2 de Groen PC, Gores GJ, LaRusso NF, et al: Biliary tract cancers. N Engl J Med 1999;341:1368-1378.

3 Hidalgo M: Pancreatic cancer. N Engl J Med 2010; 362:1605-1617.

\footnotetext{
4 Sohn TA, Lillemoe KD, Cameron JL, et al: Surgical palliation of unresectable periampullary adenocarcinoma in the 1990s. J Am Coll Surg 1999;188: 658-666; discussion 666-669.

5 Andersen JR, Sørensen SM, Kruse A, et al: Randomised trial of endoscopic endoprosthesis versus operative bypass in malignant obstructive jaundice. Gut 1989;30:1132-1135.
}

\footnotetext{
6 Shepherd HA, Royle G, Ross AP, et al: Endoscopic biliary endoprosthesis in the palliation of malignant obstruction of the distal common bile duct: a randomized trial. Br J Surg 1988;75:1166-1168.

7 Taylor MC, McLeod RS, Langer B: Biliary stenting versus bypass surgery for the palliation of malignant distal bile duct obstruction: a meta-analysis. Liver Transpl 2000;6:302-308.
} 
8 Moss AC, Morris E, Leyden J, et al: Malignant distal biliary obstruction: a systematic review and meta-analysis of endoscopic and surgical bypass results. Cancer Treat Rev 2007;33:213-221.

$\checkmark$ Loew BJ, Howell DA, Sanders MK, et al: Comparative performance of uncoated, self-expanding metal biliary stents of different designs in 2 diameters: final results of an international multicenter, randomized, controlled trial. Gastrointest Endosc 2009;70:445-453.

10 Moss AC, Morris E, Mac Mathuna P: Palliative biliary stents for obstructing pancreatic carcinoma. Cochrane Database Syst Rev 2006;CD004200.

-11 Speer AG, Cotton PB, MacRae KD: Endoscopic management of malignant biliary obstruction: stents of 10 French gauge are preferable to stents of 8 French gauge. Gastrointest Endosc 1988;34 412-417.

12 Pereira-Lima JC, Jakobs R, Maier M, et al: Endoscopic biliary stenting for the palliation of pancreatic cancer: results, survival predictive factors, and comparison of 10-French with 11.5-French gauge stents. Am J Gastroenterol 1996;91:2179-2184.

13 Isayama H, Komatsu Y, Tsujino T, et al: A prospective randomised study of 'covered' versus 'uncovered' diamond stents for the management of distal malignant biliary obstruction. Gut 2004;53: 729-734.

14 Speer AG, Cotton PB, Russell RC, et al: Randomised trial of endoscopic versus percutaneous stent insertion in malignant obstructive jaundice. Lancet 1987;2:57-62.
15 van der Gaag NA, Rauws EAJ, van Eijck CHJ, et al: Preoperative biliary drainage for cancer of the head of the pancreas. N Engl J Med 2010;362:129-137.

16 Shone DN, Nikoomanesh P, Smith-Meek MM, et al: Malignancy is the most common cause of gastric outlet obstruction in the era of $\mathrm{H} 2$ blockers. Am J Gastroenterol 1995;90:1769-1770.

17 Jeurnink SM, van Eijck CHJ, Steyerberg EW, et al: Stent versus gastrojejunostomy for the palliation of gastric outlet obstruction: a systematic review. BMC Gastroenterol 2007;7:18.

18 Hüser N, Michalski CW, Schuster T, et al: Systematic review and meta-analysis of prophylactic gastroenterostomy for unresectable advanced pancreatic cancer. Br J Surg 2009;96:711-719.

19 Adler DG, Baron TH: Endoscopic palliation of malignant gastric outlet obstruction using selfexpanding metal stents: experience in 36 patients. Am J Gastroenterol 2002;97:72-78.

20 Nakeeb A, Pitt HA, Sohn TA, et al: Cholangiocarcinoma. A spectrum of intrahepatic, perihilar, and distal tumors. Ann Surg 1996;224:463-473; discussion 473-475.

21 Berr F, Tannapfel A, Lamesch P, et al: Neoadjuvant photodynamic therapy before curative resection of proximal bile duct carcinoma. J Hepatol 2000;32:352-357.

22 Ortner MEJ, Caca K, Berr F, et al: Successful photodynamic therapy for nonresectable cholangiocarcinoma: a randomized prospective study. Gastroenterology 2003;125:1355-1363.
3 Zoepf T, Jakobs R, Arnold JC, et al: Palliation of nonresectable bile duct cancer: improved survival after photodynamic therapy. Am J Gastroenterol 2005;100:2426-2430.

24 Dolak W, Schreiber F, Schwaighofer H, et al: Endoscopic radiofrequency ablation for malignant biliary obstruction: a nationwide retrospective study of 84 consecutive applications. Surg Endosc 2014;28:854-860.

25 Tal AO, Vermehren J, Friedrich-Rust M, et al: Intraductal endoscopic radiofrequency ablation for the treatment of hilar non-resectable malignant bile duct obstruction. World J Gastrointest Endosc 2014;6:13-19.

26 Berg K, Nordstrand S, Selbo PK, et al: Disulfonated tetraphenyl chlorin (TPCS2a), a novel photosensitizer developed for clinical utilization of photochemical internalization. Photochem Photobiol Sci 2011;10:1637-1651.

27 Adigbli DK, MacRobert AJ: Photochemical internalisation: the journey from basic scientific concept to the threshold of clinical application. Curr Opin Pharmacol 2012;12:434-438.

28 von Hoff DD, Ervin T, Arena FP, et al: Increased survival in pancreatic cancer with nab-paclitaxel plus gemcitabine. N Engl J Med 2013;369:1691-1703.

29 Conroy T, Desseigne F, Ychou M, et al: FOLFIRINOX versus gemcitabine for metastatic pancreatic cancer. N Engl J Med 2011;364:1817-1825. 